discussion. Classic geological areas-the Grand Canyon, the Niagara Falls region, the Appalachians, the North-west Highlands and the Alpsare considered in detail, so that a series of lessons in tectonics of increasing complexity is presented to the student. The most important illustrations of the book are ten folding plates, mostly block diagrams, contained in a pocket at the end. The intention of the book is excellent but, unfortunately, the intention is not everywhere fulfilled.

At the outset, a feeling of irritation--if not distrust-is produced by the presence of a loose sheet bearing a long list of errata, such as "for Murchison read Sedgwick, for James read George", and this feeling is intensified by the discovery, soon made, that all errors are not on this loose sheet and that the loose sheet itself requires correction. The work is curiously uneven. Certain aspects of historical geology are well demonstrated and there are many passages in which the philosophy of field geology is charmingly and clearly put. But there are other pages that are clumsy and obscure, whilst the inclusion of a semi-popular guide to the Yellowstone Park seems scarcely necessary. It is greatly to be regretted that the excellent purpose of the book is not more nearly attained.

H. H. R.

\section{The Science of Farming}

Agriculture: the Science and Practice of British Farming. By Prof. James A. S. Watson and James A. More. Third edition, revised and enlarged. Pp. $\mathrm{x}+777+35$ plates. (Edinburgh and London : Oliver and Boyd, 1933.) 15s. net.

\section{THE fact that this book has now reached its}

third edition shows that it serves a useful purpose; it is indeed a greater tribute than it would be for a purely scientific work, in view of the well-known reluctance of agricultural students to purchase books.

Much of the book has been revised, and fresh sections have been added dealing with the new fertilisers and cultivation implements, new varieties of barley and modern methods of treating grassland, while since the first edition new chapters have been added on sugar beet and on farm costs, In accordance with modern tendencies on the farm, more space is devoted to pigs, while poultry have been given an entire chapter and a new chapter is added setting out the details of breeding, of rearing and of the various methods of keeping a commercial laying flock, including the vitally important question of costs. The account of the systems of farming in Great Britain has been expanded and greatly improved by the addition of details concerning the amounts of capital required and the probable costs and returns under present-day conditions. There is also a useful account of the comparative costs of working by horse and by tractor, and the chapter on costing contains much information about the difficulties of arriving at any result and the significance of the figures when they are obtained: actual examples are given of costs of grazing, sugar beet production and milk production. A useful addition to the tables is one showing the amounts of work normally expected per day when a man is doing various operations.

The book is clearly written, the information is sound and well set out so that the reader easily finds what he wants. It includes much material not easily otherwise obtainable and can be strongly recommended to agriculturists who do not already use it.

Since the first edition appeared, the volume has increased by some 120 pages and is now not far short of 800 pages. If, as seems likely, a fourth edition is called for, the authors might consider cutting out much of the general parts on soils, fertilisers and animal nutrition which the student should get from his agricultural chemistry course, and of the section on Mendelism which should come into the biology course; the day is gone when one and the same man is expected to expound both sex linkage and hydrogen ion concentrations, to say nothing of colloids and metabolisable energy. These sections are quite well written and could make a separate and useful guide to farmers on the principles of science that underlie farming operations; and their removal would liberate space for further additions on the practical side, and especially for fuller descriptions of actual farm practices, husbandry systems and other matters here treated more fully than elsewhere. So the book could continue its useful career without becoming too unwieldy.

\section{Nutrition and Disease}

Nutrition and Disease: the Interaction of Clinical and Experimental Work. By Dr. Edward Mellanby. Pp. xix $+171+52$ plates. (Edinburgh and London: Oliver and Boyd, 1934.) 8s. $6 d$. net.

D. E. MELLANBY delivered the Croonian lectures before the Royal College of Physicians, and the Linacre lecture at Cambridge, in 1933 and gave an account of his researches on various problems of nutrition and disease. Their publication is most welcome since such important matter should be considered at leisure. The book opens with a summary of the well-known and valuable work of Dr. and Mrs. Mellanby on rickets and dental caries and the 